\title{
Use of Super Absorbent Polymer in Concrete
}

\author{
M.S Sai Kumar ${ }^{1}$, Niranjan Shekar ${ }^{2}$, Anjan B.K ${ }^{3}$ \\ 1,2, Graduate Student, Department of Civil Engineering, VVCE, Mysore, India \\ ${ }^{3}$ Assistant Professor, Department of Civil Engineering, VVCE, Mysore, India
}

\section{ABSTRACT}

Water is becoming scant day-by-day, there is an urgent ought to save water in making concrete and in construction works. Curing of concrete is outlined as the process of maintaining the temperature and moisture conditions of concrete for hydration reaction so concrete develops hardened properties over time. However, proper curing isn't always attainable in several cases. Curing of concrete plays a serious role in developing the concrete micro-structure and pore structure and hence improves its sturdiness and performance. By considering relevancy of curing, an attempt has been made to develop self-curing concrete by using Super Absorbent polymer as self-curing agent. Compressive strength of concrete containing self-curing agents is investigated and compared with conventionally cured concrete. Selfcuring agent will increase the water retention capability of the concrete by reducing evaporation of water from concrete.

Key words: Micro Structure, Durability, Self-Curing, Super Absorbent Polymer

Corresponding Author: M.S. Sai Kumar

\section{INTRODUCTION}

Concrete could be a basic engineering material employed in the foremost of the engineering structures. Its quality as basic building in construction is owing to its economy of use, good durability and ease with which it can be manufactured in site. The flexibility to mold it into any form and size, owing to its physical property in green stage and its sequent hardening to achieve strength is especially helpful.

Concrete is a material composed of coarse aggregate bonded together with a fluid cement that hardens over time. Many a times concretes used are lime-based concretes like cement concrete. When aggregate is mixed alongside dry cement and water, the mixture forms a fluid slurry that is easily poured and molded into form. The cement reacts with chemicals with binary compound and other ingredients to form a tough matrix that binds the materials together into a sturdy stone-like material that has several uses.

A common misconception is that concrete dries as it sets, but the opposite is true, damp concrete sets better than dry concrete. In alternative words, "hydraulic cement" needs water to become strong. An excessive amount of water is counterproductive, but insufficient water is deleterious. Curing permits concrete to achieve optimal strength and hardness. Curing is that the process of maintaining the enough wet content and temperature in concrete for a period of time after the placing and finishing, so the desired properties could develop. Proper curing can improve strength, durability, abrasion resistance, resistance to freeze-thaw cycles and also reduce concrete shrinkage. Chemically, curing permits Calcium-Silicate Hydrate (C-S-H) to form. to achieve strength and harden absolutely, concrete curing 
requires time. In around four weeks, typically over 90th of the final strength is reached, although strengthening may continue for decades.

Traditionally, concrete is being cured outwardly either through the employment of water or sealed curing. Good curing isn't always practical. Many investigations give an answer to that problem, it will be self-curing concrete. Internal curing or self-curing is a technique which will provide additional water in concrete for an effective hydration of the cement and reduced self-desiccation. Self-curing signifies the ingress of a curing agent into concrete that will provide this additional moisture. Now a day, there are two major strategies available for self-curing of cement. The method uses saturated porous light Weight aggregate (LWA). It will be an internal source of water, which can replace the water consumed by chemical shrinkage during the process of cement hydration. This internal curing water is naturally moved during cement hydration from the relatively large pores of the LWA into the smaller pores of the cement paste. In the succeeding method Super Absorbent polymer (SAP) is employed, these particles can absorb a very large amount of water during concrete mixing and form massive inclusions containing free water, thus preventing self-desiccation during cement hydration.

Self-curing provides additional curing water uniformly throughout the entire microstructure of the concrete. Adoption of self-curing admixtures is incredibly vital as water resources are getting valuable every day. (i.e.., for every $1 \mathrm{~m}^{3}$ of concrete about $3 \mathrm{~m}^{3}$ of water is required for construction most of that is for curing).

\section{MATERIALS AND METHODS}

\subsection{General}

The present study deals with the strength characteristics of cement matrix using Super Absorbent Polymer (SAP). In this study, an attempt has been made to check the feasibility of using SAP as a mineral admixture and to check the strength characteristics.

\subsection{Materials}

The materials used and methodology adopted in this research work is as per "Bureau of Indian Standard". The materials used are;
Coarse Aggregate :20mm downsize
Fine Aggregate
: M - sand double washed
Cement
Water
: 43 Grade UltraTech PPC
SAP
: VVCE Concrete Lab Water Tap Water
: Sodium Polyacrylate Polymer of medical grade, Procured from Chemz Polymers, Chennai

\subsection{Tests on Coarse Aggregate}

Tests on Fineness Modulus, Specific Gravity, Water Absorption, Abrasion Value, Impact Value and Crushing Value was carried out as per IS 383: 1970 and IS 2386: 1963.

\subsection{Tests on Fine Aggregate}

Tests on Specific Gravity, Water Absorption, Grading Zone, Fineness Modulus and Silt Content was carried out as per IS 383: 1970 and IS 2386: 1963. 


\subsection{Tests on Cement}

Test on Normal Consistency, Initial Setting time, Final Setting time, Specific gravity and Compressive Strength was carried out as per IS 4031:1988.

\subsection{Tests on Water}

Tests on pH, Alkalinity, Hardness, Chlorides and Total Solids was carried out as per IS 3025.

\subsection{Tests on SAP}

Tests on Water Absorption and Specific Gravity was carried out, listed in table 3.1.

\subsection{Mix Design}

M30 mix of proportion 1:1.62:3.02 is designed as per IS 10262: 1982 and W/C of the mix is adopted as 0.4 from the results obtained from trial mix. The quantity estimation for various proportion of SAP.

\subsection{Tests on Concrete}

Workability Test is done on Fresh Concrete as per IS 1199: 1959 and Compression test on Hardened Concrete is done as per IS 9013: 1978.

\subsection{Methodology}

- Cement, $\mathrm{M}$ - Sand and Jelly are weigh batched according to the mix proportion obtained in Sec 3.8 and thoroughly hand mixed

- Water is added as per the W/C ratio of 0.4 considered in the mix design

- It is mixed for a homogenous consistency

- SAP powder is measured for the desired proportion in a container

- Water of 40 times (Centrifuge Retention Ratio) the weight of SAP is added

- The SAP is allowed to swell for about 3 minutes

- The swollen SAP is forced to pass through $300 \mu \mathrm{m}$ sieve. This is added to the fresh concrete and mixed thoroughly again

- Concrete cubes are cast with the aid of Table Vibrator with neat finishing

- After 24 Hours, the cubes are demoulded and placed in curing tank for water cured cubes and in open space for air curing

- Cubes are tested for compressive strength for different curing periods

\section{RESULTS AND DISCUSSIONS}

\subsection{Existing Practices in Mysore City}

Presently the existing practice in Mysore city is mostly conventional curing from water. Wet covering with Gunny bags and straw, ponding and sprinkling are the most commonly used. Builders and contractors occasionally adopt membrane curing when it is essential, which is limited though. 
DOI : https://dx.doi.org/10.26808/rs.ed.i8v3.03

International Journal of Emerging Trends in Engineering and Development

Available online on http://www.rspublication.com/ijeted/ijeted_index.htm

\subsection{Test Data for Sap}

The test results obtained on the characteristics of SAP are tabulated below;

Table 3.1: Test Results of SAP

\begin{tabular}{|c|c|c|}
\hline \multicolumn{2}{|c|}{ PROPERTIES } & VALUES \\
\hline \multicolumn{2}{|c|}{ Type } & Sodium Polyacrylate Polymer \\
\hline \multicolumn{2}{|c|}{ Grade } & Medical \\
\hline Particle Size & $425 \mu-300 \mu$ \\
\hline \multirow{2}{*}{ Water Absorption } & Distilled Water & 150 times \\
\cline { 2 - 3 } & Tap Water & 110 times \\
\cline { 2 - 3 } & Cement Water & 50 times \\
\hline \multirow{2}{*}{ Specific Gravity } & Dry & 1.22 \\
\cline { 2 - 3 } & Wet & 1.10 \\
\hline
\end{tabular}

\subsection{Test Data for Concrete}

To ascertain the structural strength of the concrete cubes are casted using SAP in concrete and Compressive strength test was conducted at the end of 3, 7, 28 and 60 days curing using Compression Testing Machine (Aimil, 2014), Capacity 2000kN. The results obtained are presented in Table 3.2.

The test results obtained on the Workability of Concrete from Compaction Factor

Test are tabulated below;

Table 3.2: Compression Strength Results for Different Proportions of SAP

\begin{tabular}{|c|c|c|c|c|c|c|}
\hline SL & \% OF & CURING & \multicolumn{4}{|c|}{ COMPRESSIVE STRENGTH (MPa) } \\
\cline { 4 - 7 } NO & SAP & METHOD & 3 DAYS & 7 DAYS & 28 DAYS & 60 DAYS \\
\hline 1 & 0 & Air & 19.42 & 23.60 & 29.63 & 35.60 \\
\hline 2 & 0.1 & Air & 24.33 & 27.55 & 34.36 & 39.50 \\
\hline 3 & 0.2 & Air & 22.41 & 28.07 & 37.65 & 42.40 \\
\hline 4 & 0.3 & Air & 23.29 & 27.60 & 39.72 & 44.82 \\
\hline 5 & 0.4 & Air & 22.53 & 27.31 & 38.80 & 42.40 \\
\hline 6 & 0.5 & Air & 18.47 & 22.53 & 32.64 & 37.66 \\
\hline
\end{tabular}

EIA COMPRESSIVE STRENGTH

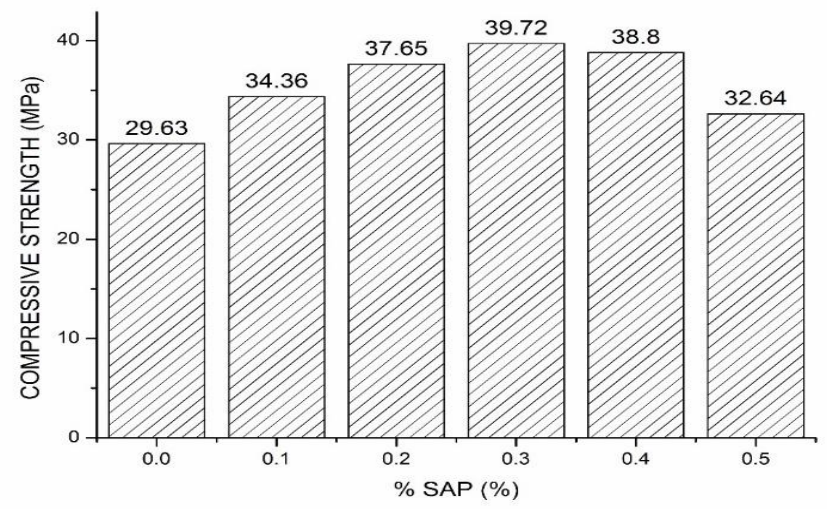

Fig. 3.2: Compressive strength of the cubes cast with different percentages SAP 


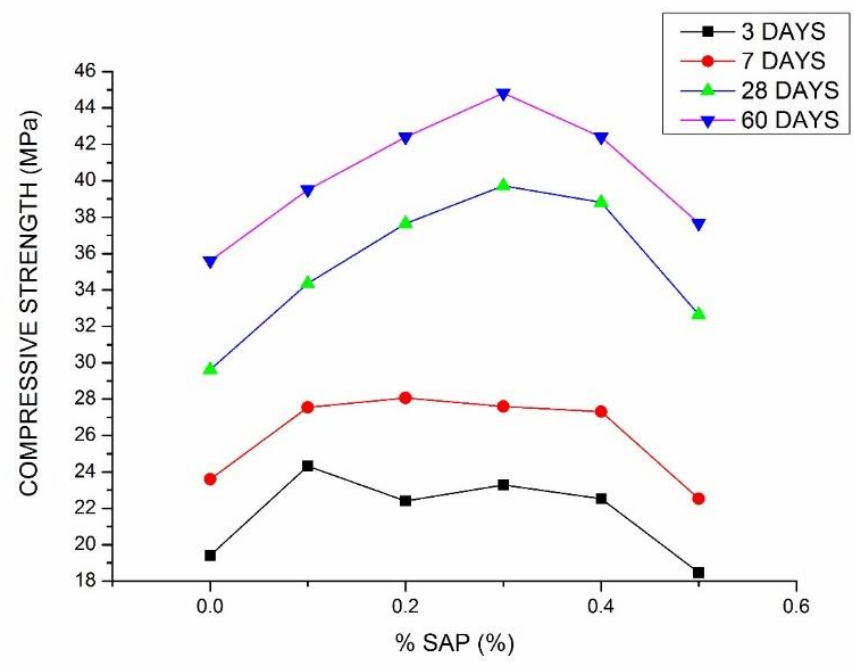

Fig. 3.3: Compressive strength for curing periods of 3 days, 7 days, 28 days and 60 days

The mechanical strength of the cubes cast with different percentages SAP results obtained are indicated in Fig 3.2. We can observe that strength of concrete gradually increased with increase in percentage of SAP up to $0.3 \%$ and gradually got decreased.

Graphs of compressive strength for curing periods of 3 days, 7 days, 28 days and 60 days for air curing for $0 \%, 0.1 \%, 0.2 \%, 0.3 \%, 0.4 \%$ and $0.5 \%$ are shown in Fig 3.3 .

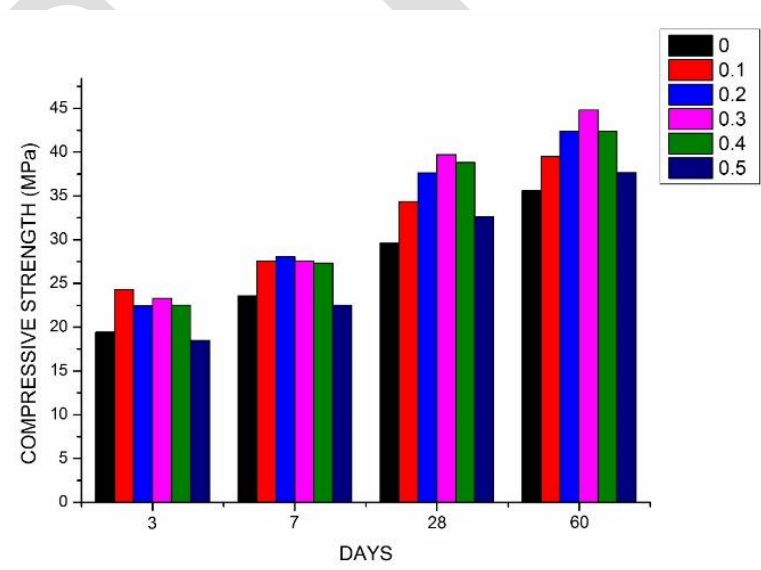

Fig. 3.4: Compressive strength for curing periods of 3 days, 7 days and 28 days for air curing for $0 \%$, $0.1 \%, 0.2 \%, 0.3 \%, 0.4 \%$ and $0.5 \%$

Also, graph of 3 days, 7 days and 28 days compressive strength for varying proportion of SAP is shown in Fig 3.4. For 3 days strength from Fig 3.2, it is observed that air curing attained higher Strength this due to the reason that the excess unreacted water in the matrix makes the specimen soft. $0.1 \%$ of SAP achieved the maximum strength for 3 days. As the amount of SAP was increased the water content increased making the specimens softer hence a trend of decreasing strength was observed. 


\section{CONCLUSIONS}

Based on the literature cited, analysis made and results obtained, the following conclusions may be drawn,

- $0.3 \%$ SAP was the optimum dosage

- For Air curing, control cube achieved 29.63MPa at 28 days and optimum dosage cube achieved $39.72 \mathrm{MPa}$ which is $34 \%$ higher

- The strength achieved for air curing with $0 \%$ SAP was 40.53MPa, this strength was achieved by air cured optimum dosage sample, with a strength of $39.72 \mathrm{MPa}$

- In Mysore city, presently there is no proper water supply for newly formed layouts (E.g. J.S.S Layout)

- Adopting SAP as self-curing agent can be advantageous in desert regions to deal with limited water availability

- Hence it can be concluded that, by using $0.3 \%$ SAP in concreting and just by air curing the concrete can achieve the same strength as that of traditionally cured concrete, hence suitable where water is insufficient

- The excess cost of the SAP is balanced by the reduction in all in aggregates and cement

- The drawback of air entrained concrete of reduced strength is not observed whereas the benefits are not compromised

- Workability was found to increase with increase in percentage of SAP

- Density of concrete was reduced from $24.13 \mathrm{kN} / \mathrm{m}^{3}$ to $23.38 \mathrm{kN} / \mathrm{m}^{3}$ for Control cube and $0.3 \%$ SAP cube respectively

- To avoid segregation and bleeding due to falling impact of concrete and over vibration water added must be restricted to centrifuge retention ratio of SAP when cement water is absorbed by it

\section{REFERENCE}

I. U. Srinivasa Rao, M. Suresh Babu (2017), "Study of strength parameters on concrete with partial replacement of cement by sodium Polyacrylate and fly ash", International Journal of Civil Engineering and Technology (IJCIET), Vol. 08, Issue 03, PP1123-1130

II. Dayalan J (2016), "Compressive Strength and Durability of Self Curing Concrete", International Research Journal of Engineering and Technology (IRJET), Vol.03, Issue 03, PP 2395-0072

III. Putturu Manoj Kumar, K.V.S Gopala Krishna Sastry (2016), "Strength Characteristics of Self Curing Concrete with Different Self Curing Agents", International Journal of Innovative Research in Science, Engineering and Technology, Vol. 05, Issue 09, PP 16511-16517

IV. Ravindra D. Warkhade, Mahesh S. Varpe, Vikas S. Dhangar, Varsha S. Dalvi, S. G. Upadhyay (2016), "Use of SAP in concrete", International journal of advance research in science and engineering, Vol.05, Issue 02, PP 424-429

V. S. M. Junaid, S. Saddam, M. Junaid, K. Yusuf, S. A. Huzaifa (2015), "Self- Curing Concrete", International Journal of Advance Foundation and Research in Science \& Engineering (IJAFRSE), Vol. 01, Issue 01, PP 1-7 
DOI : https://dx.doi.org/10.26808/rs.ed.i8v3.03

International Journal of Emerging Trends in Engineering and Development

Issue 8, Vol.3 (April- May 2018)

Available online on http://www.rspublication.com/ijeted/ijeted_index.htm

ISSN 2249-6149

VI. Kenneth Sequeira, Raghu H. Naik, B. H. V. Pai (2015), "Use of Super Absorbent Polymer in internally cured concrete- A Review", International Research Journal of Engineering and Technology (IRJET), Vol. 02, Issue 03, PP 2395-0072

VII.Moayyad Al Nasra, Mohammad Daoud (2015), "Investigating the Use of Super Absorbent Polymer in Plain Concrete", International Journal of Emerging Technology and Advanced Engineering, Vol. 03, Issue 08, PP 598-603 